4. Koster TM, Wetterslev J, Gluud C, Jakobsen JC, Kaufmann T, Eck RJ, et al. Apparently conclusive meta-analyses on interventions in critical care may be inconclusive-a meta-epidemiological study. J Clin Epidemiol. 2019;114:1-10.
5. Storz-Pfennig P. Potentially unnecessary and wasteful clinical trial research detected in cumulative meta-epidemiological and trial sequential analysis. J Clin Epidemiol. 2017;82:61-70.
See Article page 167

\section{Commentary: Not all meta-analyses can be trusted}

\author{
Stephanie K. Tom, MD, ${ }^{\mathrm{a}}$ \\ Emily Perdoncin, MD, FACC, ${ }^{\text {b }}$ and \\ Kendra J. Grubb, MD, MHA, FACC ${ }^{b}$
}

Systematic reviews and meta-analyses are widely viewed as the gold standard within the hierarchy of evidencebased medicine. These studies directly impact clinical guidelines and influence the way we practice medicine. However, clinicians may be unaware of the risk for introduction of random error, that is, type 1 error, when meta-analyses are small and underpowered, potentially inflating estimates of treatment effect. ${ }^{1}$ This risk may be further increased as evidence continues to accumulate and meta-analyses are updated over time, ultimately resulting in spurious data that can negatively affect how we deliver clinical care. ${ }^{2}$ Studies have shown that the risk of type 1 error could range from $10 \%$ to $30 \%$ of meta-analyses. ${ }^{2-4}$

The presented article by Chan and Harkey, ${ }^{5}$ "Trial Sequential Analysis in Meta-analyses: A Clinically Oriented Approach With Real World Example," provides a detailed introduction for the clinician to trial sequential analysis (TSA), an analytic method aimed at minimizing the chance of type 1 error in meta-analyses, by adjusting the test statistics accordingly as new trials or more data are added. ${ }^{5}$ The authors, using a post hoc TSA, performed

\footnotetext{
From the a Department of Surgery, Emory University, Atlanta, Ga; and ${ }^{\mathrm{b}}$ Structural Heart and Valve Center, Division of Cardiothoracic Surgery, Emory University, Atlanta, Ga.

Disclosures: The authors reported no conflicts of interest.

The Journal policy requires editors and reviewers to disclose conflicts of interest and to decline handling or reviewing manuscripts for which they may have a conflict of interest. The editors and reviewers of this article have no conflicts of interest.

Received for publication July 21, 2020; revisions received July 21, 2020; accepted for publication July 22, 2020; available ahead of print July 25, 2020.

Address for reprints: Kendra J. Grubb, MD, MHA, FACC, Structural Heart and Valve Center, Division of Cardiovascular Surgery, Emory University School of Medicine, 550 Peachtree St NE, 6th Floor, Atlanta, GA 30308 (E-mail: kjgrubb@emory.edu). J Thorac Cardiovasc Surg 2021;162:175-6 $0022-5223 / \$ 36.00$

Copyright (c) 2020 by The American Association for Thoracic Surgery https://doi.org/10.1016/j.jtcvs.2020.07.067
}

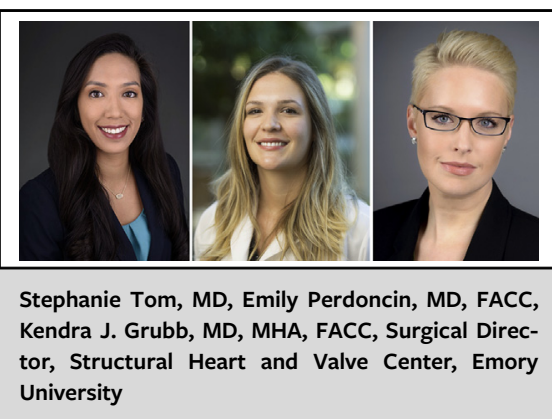

\section{CENTRAL MESSAGE}

TSA, a statistical tool for critical data analysis and confirmation, minimizes risk of type 1 error. TSA helps clinicians critically appraise data when considering applications to clinical practice.

an elegant reanalysis of data from the meta-analysis of Woldendorp and colleagues, ${ }^{6}$ which examined the associations among subclinical valve thrombosis (SCVT), stroke, and various antithrombotic strategies.

The reanalysis of the meta-analysis of Woldendorp and colleagues ${ }^{6}$ using TSA confirmed a $100 \%$ increase in the risk of stroke in patients with SCVT and a 20\% reduction in the incidence of SCVT in patients taking oral anticoagulants, as opposed to single antiplatelet therapy or dual antiplatelet therapy. Of note, with TSA, the observed $20 \%$ increase of SCVT in patients taking single antiplatelet therapy as opposed to dual antiplatelet therapy could not be considered conclusive because of underpowered data. As noted by the authors, the important limitations to TSA include susceptibility to bias and heterogeneity. In fact, the conclusion regarding the superiority of oral anticoagulants to antiplatelet therapies must be interpreted with caution, because significant heterogeneity was detected.

TSA appears to be a strong, although complex, statistical tool that allows for the critical analysis and confirmation of data with the goal of minimizing the risk of type 1 error. 
When appropriate, and with cautious attention to inherent limitations, TSA can complement available statistical models and help clinicians critically appraise the available data when considering applications to clinical practice.

\section{References}

1. Thorlund K, Imberger G, Walsh M, Chu R, Gluud C, Wetterslev J, et al The number of patients and events required to limit the risk of overestimation of intervention effects in meta-analysis - a simulation study. PLoS One. 2011;6: e25491.
2. Imberger G, Thorlund K, Gluud C, Wetterslev J. False-positive findings in Cochrane meta-analyses with and without application of trial sequential analysis: an empirical review. BMJ Open. 2016;6:e011890.

3. Brok J, Thorlund K, Gluud C, Wetterslev J. Trial sequential analysis reveals insufficient information size and potentially false positive results in many meta-analyses. J Clin Epidemiol. 2008;61:763-9.

4. Borm GF, Donders AR. Updating meta-analyses leads to larger type I errors than publication bias. J Clin Epidemiol. 2009;62:825-30.e10.

5. Chan JH, Harky A. Trial sequential analysis in meta-analyses: a clinically oriented approach with real-world example. J Thorac Cardiovasc Surg. 2021;162:167-73.

6. Woldendorp K, Doyle MP, Black D, Ng M, Keech A, Grieve SM, et al. Subclinical valve thrombosis in transcatheter aortic valve implantation: a systematic review and meta-analysis. J Thorac Cardiovasc Surg. February 19, 2020 [Epub ahead of print].
See Article page 167.

\section{Commentary: Seeing the faces in Rubin's vase}

\author{
Jacquelyn Quin, MD, MPH
}

As surgeons increasingly turn to the published literature to guide clinical practice, Chan and Harky ${ }^{1}$ provide a timely tutorial on analyzing meta-analysis data using trial sequential analysis (TSA). TSA is essentially the same statistical methodology as interim analysis, which allows investigators in clinical trials to analyze data as it accumulates in "real time" rather than having to wait for a final accounting of all anticipated results., ${ }^{2,3}$ The authors showcase TSA using a recently published meta-analysis by Woldendorp and colleagues on subclinical valve thrombosis (SCVT), stroke, and different antithrombotic strategies in patients who underwent transcatheter valve insertion. ${ }^{4}$ Using the 12 studies from the original publication, the investigators reconfigure the data from forest plots into TSA diagrams. Although the information is essentially the same, a distinctly new perspective

From the Cardiac Division, Department of Surgery, VA Boston Healthcare System, Boston, Mass.

Disclosures: The author reported no conflicts of interest.

The Journal policy requires editors and reviewers to disclose conflicts of interest and to decline handling or reviewing manuscripts for which they may have a conflict of interest. The editors and reviewers of this article have no conflicts of interest.

Received for publication June 22, 2020; revisions received June 22, 2020; accepted for publication June 23, 2020; available ahead of print July 10, 2020.

Address for reprints: Jacquelyn Quin, MD, MPH, Cardiac Division, Department of Surgery, VA Boston Healthcare System, 1400 VFW Parkway, Mail Code 112, West Roxbury, MA 02132 (E-mail: jacquelyn.quin@va.gov).

J Thorac Cardiovasc Surg 2021;162:176-7

0022-5223/\$0.00

Published by Elsevier Inc. on behalf of The American Association for Thoracic Surgery

https://doi.org/10.1016/j.jtcvs.2020.06.089
Check for updates

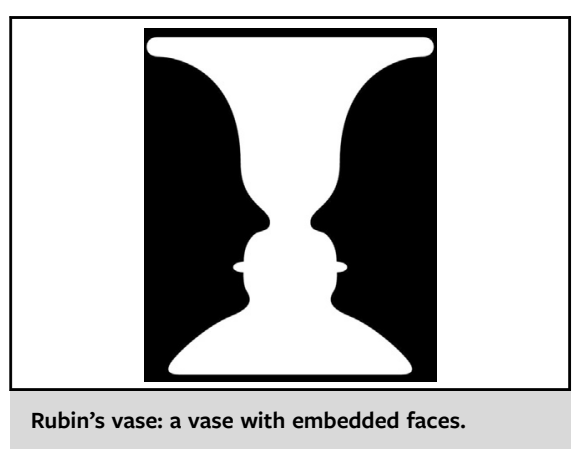

CENTRAL MESSAGE

Surgeons should be familiar with

the principles and caveats of trial

sequential analysis, an emerging

statistical methodology that of-

fers a unique view of meta-

analysis data.

emerges. With TSA, one can visualize the contribution of each individual study, added over time, in the march toward a finite answer.

In the case of the association of SCVT with stroke, the TSA diagram presented in the didactic suggests we ponder this question no further; the statistical significance boundary, set to query whether SCVT was associated with at least a $100 \%$ increase in stroke compared with normal leaflet motion, was crossed several studies ago. Additional investigation is unlikely to alter conclusions. However, investigators interested in differences between antithrombotic regimens of dual- versus single-antiplatelet therapy can see that, for a relative risk reduction (RRR) of $20 \%$, the strength of the currently available data renders this question 